OPEN ACCESS

Edited by:

Kathryn D. Bisack,

National Marine Fisheries Service, Northeast Fisheries Science Center,

USA

Reviewed by:

Daniel S. Holland,

National Oceanic and Atmospheric

Administration, USA

Kathleen Segerson,

University of Connecticut, USA

*Correspondence:

James Innes,

CSIRO Oceans and Atmosphere Business Unit, EcoSciences Precinct,

41 Boggo Road, Dutton Park,

Brisbane, QLD 4102, Australia

james.innes@csiro.au

Specialty section:

This article was submitted to

Marine Affairs and Policy,

a section of the journal

Frontiers in Marine Science

Received: 06 February 2015

Accepted: 17 September 2015

Published: 13 October 2015

Citation:

Innes J, Pascoe S, Wilcox C, Jennings S and Paredes S (2015)

Mitigating undesirable impacts in the

marine environment: a review of

market-based management

measures. Front. Mar. Sci. 2:76.

doi: 10.3389/fmars.2015.00076

\section{Mitigating undesirable impacts in the marine environment: a review of market-based management measures}

\author{
James Innes ${ }^{1,2 *}$, Sean Pascoe ${ }^{1}$, Chris Wilcox ${ }^{3}$, Sarah Jennings ${ }^{4}$ and Samantha Paredes ${ }^{1,5}$ \\ ${ }^{1}$ CSIRO Oceans and Atmosphere Business Unit, Brisbane, QLD, Australia, ${ }^{2}$ Institute for Marine and Antarctic Science, \\ University of Tasmania, Taroona, TAS, Australia, ${ }^{3} \mathrm{CSIRO}$ Oceans and Atmosphere Business Unit, Hobart, TAS, Australia, \\ ${ }^{4}$ Tasmanian School of Business and Economics, University of Tasmania, Hobart, TAS, Australia, ${ }^{5}$ School of Economics and \\ Finance, Queensland University of Technology (QUT), Brisbane, QLD, Australia
}

Internationally, marine biodiversity conservation objectives are having an increasing influence on the management of commercial fisheries. While this is largely being implemented through Marine Protected Areas (MPAs) other management measures, such as market based instruments (MBls), have proved to be effective at managing target species catch in fisheries and reducing environmental impacts in industries such as mining and tourism. Market-based management measures aim to mitigate the impacts of activities by better aligning the incentives their participants face with the objectives of management, changing their behavior as a consequence. In this paper, we review the potential of MBls as management tools to mitigate undesirable environmental impacts associated with commercial fishing. Where they exist, examples of previous applications are described and the factors that influence their applicability and effectiveness are discussed. Several fishing methods and impacts are considered and suggest that whilst no single approach is most appropriate in all circumstances either replacing or complementing existing management arrangements with MBls has the potential to improve environmental performance. This has a number of implications. From the environmental perspective they should enable levels of undesirable impacts such as damage to sensitive habitat or the bycatch of protected species of turtles, marine mammals, and seabirds to be reduced. The increased flexibility MBls allow industry when developing solutions also has the potential to reduce costs to both the industry and managers, improving the cost-effectiveness of regulation as a result. Further, in the increasingly relevant case of MPAs the need for publicly funded compensation, often paid to industry when vessels are excluded from grounds, may also be significantly reduced if improved environmental performance makes it possible for some industry members to continue operating.

Keywords: MPAs, marine conservation, quotas, taxes, penalties, bonds, protected species 


\section{Introduction}

Over the last two decades, the development of international ${ }^{1}$ and regional $^{2}$ conventions to protect marine biodiversity has resulted in greater commitments to mitigate undesirable impacts in the marine environment, mostly through increasing the amount of habitat closed to fishing. For example, the Convention on Biological Diversity has a global target of $10 \%$ of the marine environment being included in marine protected areas (MPAs) by 2020. In the USA, legislation is being developed at both State and Federal levels with this objective (e.g., Hildreth, 2008). The Marine Strategy Framework Directive ${ }^{3}$ has a similar goal in Europe. MPAs are also being implemented in developing nations for both conservation and economic reasons, such as tourism and to protect coastal community livelihoods (Francis et al., 2002). Similarly, a National Representative System of MPAs has been implemented in Australia with the main goals of protecting biological diversity and maintaining marine ecological processes and systems ${ }^{4}$.

While the non-market benefits of MPAs are potentially numerous (Angulo-Valdés and Hatcher, 2010) the costs of setting them up may also be high. Establishing MPAs generally requires fishing effort to be reduced in the area under consideration, either through buy-back programs or by the displacement of fishing effort to other areas (Sen, 2010). While the true cost of such schemes is often difficult to accurately quantify, it can be substantial (Dowling et al., 2011). Where fishing effort has been bought out, this has also often involved publicly funded compensation for related industries. For example, compensation payments associated with expanding no take zones from 4 to $34 \%$ of the Great Barrier Reef marine park are estimated to have exceeded $\$ 250$ million (MacIntosh et al., 2010). Much of this was paid to onshore businesses that claimed to be adversely affected by the change (Gunn et al., 2010). Consequently, identifying policies that can reduce these costs whilst still achieving management goals is an important component of developing cost-effective approaches to marine spatial planning and management.

There is little incentive for stewardship, or to actively prevent overexploitation, when a species or habitat is not privately owned, effectively making it a common property resource (Hardin, 1968; Gordon, 1991). Market-based management measures aim to create a situation where operators' incentives are better aligned with the objectives of management, changing their behavior to mitigate the impacts of activities as a consequence. In the context considered here, management objectives may include reducing protected species mortalities or preventing damage to

\footnotetext{
${ }^{1}$ E.g., United Nations Conference on Development and Environment; the Convention on Biological Diversity; United Nations Conventions on the Law of the Sea.

${ }^{2}$ E.g., Convention on the Protection, Management and Development of the Marine and Coastal Environment of the Eastern African Region (Nairobi Convention), Natura 2000 (EU).

${ }^{3}$ Directive 2008/56/EC of the European Parliament and of the Council of 17 June 2008 establishing a framework for community action in the field of marine environmental policy.

${ }^{4}$ Whilst these reserves are now in place the management plans were set aside before coming into effect as part of the ongoing Commonwealth Marine Reserves Review.
}

sensitive habitat. This is in contrast to the more familiar fisheries management problem of preventing the target stock/s from being overexploited, although the central challenge is essentially the same in both cases.

If the environmental impact of a fishery can be adequately reduced by incentivizing behavioral change, marine conservation objectives may still be met without the need to fully remove fishing from an area. Potentially, fisheries could then continue to operate at some level within the bounds of declared reserves. Behavioral changes that reduce the need to prevent activities or displace effort also have the potential to reduce the costs of conservation to both management (e.g., compensation, administration) and industry (e.g., loss of income, increased competition on fishing grounds that remain open). If the overall cost per unit of benefit gained under MBIs is lower than the alternative (e.g., compensation for the complete exclusion of vessels from an area) they will also be a more costeffective approach. This would allow the cost of achieving a given reduction in impact to be reduced or, depending upon the management objectives, greater areas of habitat or species range to be protected with the same level of funding.

In this paper, we review the potential of MBIs as management tools to mitigate the undesirable environmental impacts associated with commercial fishing and consider how this might reduce the need to exclude fisheries from MPAs. Where they exist, examples outlining previous applications of MBIs are described and the factors that influence their applicability and effectiveness are discussed. While our focus is on fishing, these tools are potentially applicable to other industries whose actions can impact the marine environment in undesirable ways (e.g., dredging for port development).

The paper is organized as follows: The next section, Fisheries Impacts on Marine Environments, outlines some of the key fisheries impacts that could potentially be reduced through the use of MBIs. This is followed by the section Market-based Instruments and Fisheries Management Measures, which outlines a range of potential MBIs, first considering measures based on financial incentives before discussing quota oriented approaches. The discussion section then addresses some additional factors for consideration and limitations that influence how these tools may be applied.

\section{Fisheries Impacts on Marine Environments}

The impacts fishing can have on the marine environment are well-documented (e.g., Tasker et al., 2000; Kaiser et al., 2002). In addition to catching their target species, fishing vessels can impact non-targeted species, some of which may be threatened, endangered, or protected species caught incidentally. In some cases, marine habitats are directly damaged, while associated ecological communities are impacted through ecosystem interactions (Hobday et al., 2011). These impacts may involve species of no direct commercial value but of considerable non-market value (e.g., iconic and often protected species such as turtles, dolphins, and seabirds). As the cost of this damage is often not borne by the fisher, levels of damage are typically greater than 
the social optimum ${ }^{5}$. MPAs can limit or reduce this damage by preventing access to areas that are considered to have substantial non-market values (e.g., large populations of iconic species such as turtle nesting areas), but in doing so impose costs on fisheries and management agencies.

The specific impacts that a fishery has, how predictable these events are, and the frequency with which they occur vary by fishery and region. For example, in Australia the southern demersal trawl fisheries have heavier impacts on non-target demersal fish species and sharks, while seabirds are among the most heavily impacted bycatch species for the southern longline pelagic fishery (Table 1). Similarly, the impact on certain habitats varies with the type of fishing gear being applied. For example, habitats may be impacted by trawling but not by line fishing.

The frequency of an impact's occurrence is a function of the species or habitat present, the gear used, and how and when the gear is applied. The type of gear used directly influences the species or habitats a fishery is capable of interacting with, whilst the region and season it operates in influences the species and habitats that may potentially be impacted. MBIs attempt to reduce overall impact by making fishers accountable for the consequences of their actions which can influence behavior with respect to the gear type choice and configuration along with when the gear is applied. Last, fishers may have limited control over the degree of uncertainty associated with causing an impact and this is one of the factors that have a direct bearing on the applicability of specific MBIs.

\section{Market-based Instruments and Fisheries Management Measures}

Command-and-control measures generally dominate fisheries management internationally. These include forms of both input (e.g., gear or effort constraints) and output (total allowable catches) oriented measures. They are prescriptive by nature, so tend to be inflexible, not allowing individual solutions to problems, and are potentially inefficient as a consequence. Input oriented management measures are typically least favored by economists, as there is the risk of constrained inputs being wastefully substituted with unconstrained ones. While catch and conservation objectives may be achieved in some cases, these can be at the cost of high levels of inefficiency in the industry and consequent overuse of resources (Townsend, 1985). In many cases, even the key objectives are not achieved. Attempts to manage overall levels of target species catch (or bycatch) in fisheries by limiting effort via relatively easy to measure inputs such as hooks set or days fished typically fail as fishers increase their use of non-regulated inputs instead.

Output measures that focus directly upon monitoring and controlling the quantities of catch or bycatch a fishery takes

\footnotetext{
${ }^{5}$ Such market failure has been identified in a wide range of industries, and is not exclusive to fisheries. For example, the costs of pollution externalities are not generally considered by the polluter in their production process. The divergence between private and public optimum due to externalities has been long recognized in the economics literature (e.g., Pigou, 1924).
}

provide greater certainty that management objectives relating to the fishery resource will be achieved. Further, when catch shares are individually allocated, they also have the ability to induce more efficient behavior (Grafton, 1996). For example, when a total allowable catch (TAC) is allocated to individuals, wasteful incentives to race to fish are reduced and replaced with individual incentives to minimize costs. If not constrained by input controls, output oriented approaches can also result in greater efficiency by being more flexible and allowing fishers to develop or apply methods of impact mitigation that work best in their specific circumstances. The most cost-effective way of catching target species or reducing impacts will potentially vary between fleets and even between individual vessels.

MBIs generally work by creating a price (either explicitly or implicitly) for the use of a non-market resource in the production process. This price reflects the cost imposed by the activity and primarily borne by society until then. Requiring operators to account for this cost creates an incentive to reduce their impact. In the case of fisheries, these undesirable impacts include bycatch of non-target species (including iconic/protected species) as well as habitat damage. MBIs differ from command-andcontrol measures in the way that they rely on price signals, applied at the individual or firm level, to incentivize changes in behavior and outcomes. They may be applied in addition to existing command-and-control measures (e.g., ITQs on top of spatial constraints) or instead of them (e.g., penalties instead of regulations specifying how and when to operate gear). Where vessels are heterogeneous in their ability to reduce impacts, tradable quotas facilitate further efficiency by creating additional financial incentives for quota to pass to vessels that can use it most efficiently, working in the same way as ITQs for target species.

A hierarchy of potential market-based management systems is presented in Figure 1. Incentives can be created by either placing constraints on the level of impact fishing activities have, or by influencing the rewards from fishing. Constraints such as bycatch quotas are flexible and differ from hard constraints, such as area closures, as fishers are potentially able to adjust the level of their individual constraint through quota trading. Non-tradable quotas are not strictly MBIs, in the sense that there is no market for them, but they can still create incentives to reduce impact at the individual level if not doing so would result in vessels having to prematurely stop fishing (and thus they have an implicit value associated with them). Financial incentives include the use of charges, subsidies or bonds. Charges and subsidies directly affect the returns from different fishing activities, thereby stimulating behavioral or technological change. Bonds incentivize similar types of change by providing the incentive for fishers to reduce their impacts sufficiently below some threshold. The expected behavioral response varies slightly depending on the type of policy instrument chosen. Tradable quotas and penalties are generally anticipated to result in individuals attempting to minimize the level of impact they create; as fewer penalties reduces costs and the ability to operate with a low level of quota either reduces costs or increases income. On the other hand, bonds and insurances are expected to create the incentive to ensure that impacts are limited to an agreed level. However, even 
TABLE 1 | Examples of how the frequency of non-commercial bycatch can vary by gear type and region in some Australian fisheries ${ }^{6}$.

\begin{tabular}{|c|c|c|c|c|c|c|}
\hline Frequency of occurrence & \multicolumn{2}{|c|}{ Demersal trawl } & Demersal longline & \multicolumn{2}{|c|}{ Pelagic longline } & $\begin{array}{l}\text { Demersal gillnet } \\
\text { South }\end{array}$ \\
\hline & Seabirds & Turtles & & Seabirds & & \\
\hline & & Dolphins & & & & \\
\hline & Sharks & Sharks & Sharks & & Seabirds & Sharks \\
\hline Frequent & Other fish & Other fish & Other fish & Sharks & Sharks & \\
\hline
\end{tabular}

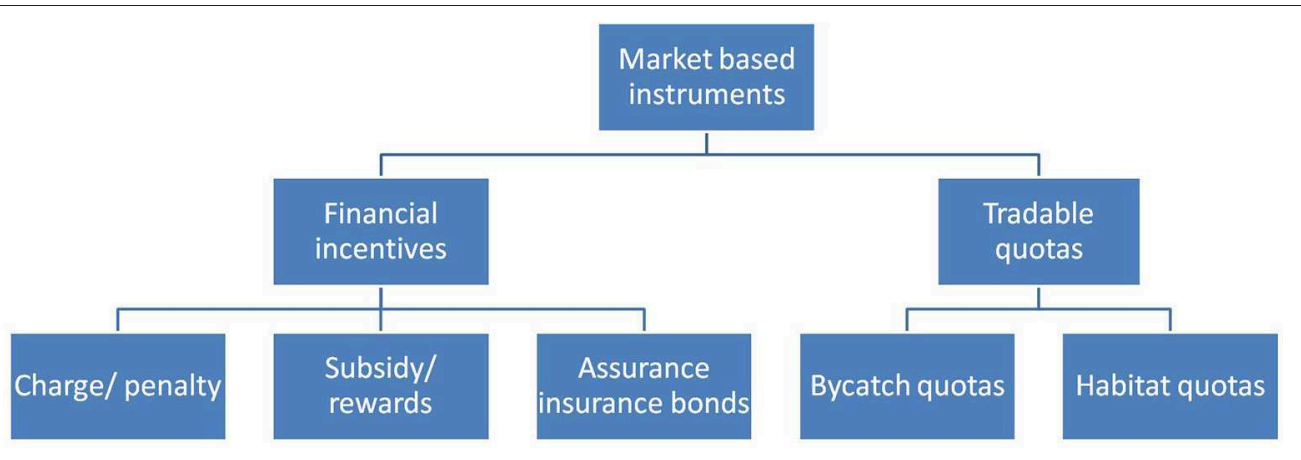

FIGURE 1 | Hierarchy of market-based fisheries management systems for reducing environmental damage.

in this case there is still some incentive to try and keep below this limit to avoid accidentally exceeding it.

Previous assessments of MBIs have also included eco-labels and trade-barriers (Pascoe et al., 2010). However, these are largely related to fishery-wide behavior and often require additional management measures to create the individual incentives required to achieve the desired outcomes. Similarly, when damages are known or even perceived to occur by the public, the loss of "social license to operate" may translate into financial cost in terms of reduced revenues (through lower demand for the product) and potentially greater regulation or restrictions. These again require fishery level solutions, but may utilize MBIs to create the appropriate individual incentives. For the sake of brevity, these fishery level issues are not considered here.

Finally, to be effective all policy instruments depend on adequate levels of compliance. A range of factors have been identified as influencing compliance in the fisheries context, central to which are economic incentives and deterrence (Sutinen et al., 1990; Nielsen and Mathiesen, 2003). Exactly what needs to be monitored to create a deterrent varies between alternative applications (i.e., the chosen MBI and the specific impact it is being applied to) but in all cases it is important that the likelihood of an impact being detected is high. When this condition is met MBIs can directly alter the economic incentives fishers face.

\footnotetext{
${ }^{6}$ In addition to species specific assessments (e.g., Stewardson, 2007; Trebilco et al., 2010), the Australian Fisheries Management Authority (AFMA) Bycatch and Discard Program is a central source of information for bycatch in Commonwealth fisheries http://www.afma.gov.au/sustainability-environment/bycatch-discarding/
}

\section{Financial Incentives}

\section{Charge or Penalty-based Systems}

In addition to the potential opportunity cost associated with disposing of bycatch, damage to gear (e.g., from bycatch or habitat), reduced harvest due to bait and hooks being consumed by non-target species, or damaged and devalued target species ${ }^{7}$ are all potential costs of poor environmental performance. However, as these costs are often relatively small or poorly accounted for there is consequently little incentive for fishers to limit their impact when operating. Bycatch and other environmental impacts can thus be considered unpriced inputs in the production process.

Placing an appropriate price on these environmental impacts provides incentives for fishers to modify their behavior (i.e., production and fishing effort allocation), and to adopt impactreducing technologies that reduce these costs. Where such technologies do not exist, correctly set charges will encourage their development. For example, the use of carbon charges has been seen to influence both energy mix in manufacturing and total demand by households (Johansson, 2000; Bruvoll and Larsen, 2004; Tietenberg, 2013). Carbon charges have also been seen to induce technological change that substantially accelerates the substitution of carbon-free energy for fossil fuels (Gerlagh and Lise, 2005). An advantage of a penalty system is that, at least in theory, different impacts (and species) can attract different

\footnotetext{
${ }^{7}$ For example, if fish can be bruised by interactions with bycatch whilst in the cod end, reducing their quality and value. Crab bycatch can also damage and devalue target species in shrimp trawls.
} 
penalty rates, thereby ensuring the greatest protection to that which is most vulnerable.

Whilst there is no direct incentive to target non-commercial species, the value of any associated target species can result in them still being caught, especially if there is no explicit cost associated with doing so. The potential benefits of monetary penalties for reducing the level of bycatch of non-commercial species, particularly megafauna (e.g., seals, turtles, seabirds), have been demonstrated theoretically by a number of authors (Sanchirico, 2003; Diamond, 2004; Herrera, 2005; Singh and Weninger, 2009). Limited examples exist of charges being implemented on commercial but non-targeted species. Where applied, it has been with the intention of either encouraging fishers to avoid the species (Schrank et al., 2003), or providing a mechanism through which species without quota can be landed (Sanchirico et al., 2006).

Where fishers are able to avoid non-commercial species and incidents are observable, a bycatch charge is likely to influence their behavior and reduce the catch of these species. Similarly, penalties linked to operating in certain areas will create incentives for fishers to look elsewhere without permanently locking fishing activity out of these areas. Given seasonality in ecological systems, such a charge can be readily adjusted to provide a greater disincentive to operate in an area in times of high sensitivity (e.g., spawning seasons), and a weaker disincentive in less critical times. However, as with many of the policies discussed in this review, the effectiveness of the MBI will depend on the actual ability of the fisher to avoid the species or areas of concern.

The implementation of both habitat use and bycatch penalties requires information on fishing activities and catches. Historically, these data have been relatively expensive to collect, due to the need for independent observers on each vessel during fishing operations. However, the continued refinement of technology such as electronic monitoring systems (EMS) has the potential to make it increasingly cost-effective when compared to observer coverage, and to revolutionize the use of this type of incentive (Bryan et al., 2011; Kindt-Larsen et al., 2011; Piasente et al., 2011; Seafish, 2012). Vessel monitoring systems (VMS), which can track individual vessel location, are now common among larger fisheries and can provide a means of determining when and where a vessel is fishing (Witt and Godley, 2007). With such information, charges can be readily applied if vessels operate in ecologically sensitive areas.

Penalties are not likely to be appropriate for impacts that are highly stochastic in nature (i.e., essentially random) as it makes them difficult to predict and consequently hard to avoid. In this situation, imposing penalties that are large enough to create a strong incentive to reduce impact may also result in operators facing untenable financial risk every time they go fishing. A further factor for consideration with penalties is that to create a strong incentive to reduce impact, they would need to be payable soon after issue. Allowing penalties to accrue increases the risk of default and diminishes the impact/cost association. From a practical perspective, this means that penalties are likely to function better in cases where impacts are reasonably predictable and infrequent rather than situations characterized by high levels of uncertainty or high frequency of occurrence, the same problem
Holland (2010) identifies for bycatch ITQs. Impracticably large numbers of penalties would need to be issued in the latter case creating unnecessary additional costs for both industry and regulators, making the measure inefficient.

\section{Direct Subsidies and Payments}

The use of subsidies to reduce environmental impacts is limited in fisheries. Where subsidies exist, these are usually related to reducing the cost of less damaging fishing gear to encourage its adoption (Cox and Schmidt, 2006). However, even so called "environmentally friendly" subsidies can result in increased exploitation by reducing the cost of fishing (Cox and Schmidt, 2006), and potentially increase total damage as a result.

Payments to individuals to ensure the protection or enhancement of ecosystem goods or services are an established market-based instrument for habitat and species protection in terrestrial conservation (Farley and Costanza, 2010; Muradian et al., 2010). The potential of such an approach to managing the impacts of fisheries is still emerging as it requires welldefined and secure property rights over the good or service being protected ${ }^{8}$ and effective enforcement (Bladon et al., 2014). Critics of the approach also suggest that payment for such services can undermine the moral sentiments for conservation, moving it from ethical consideration to economic self-interest (Gómez-Baggethun et al., 2010). Gains may also be lost over the longer term if agreements cannot be maintained over time and are allowed to lapse. The resumption of dolphin hunting in the Solomon Islands in 2013 after the breakdown of an agreement between villagers and a conservation group that had been providing financial support to develop alternative activities illustrates this point (Oremus et al., 2015). Whilst the breakdown of any MBI discussed in this paper will potentially result in their benefits being lost, the risk of this occurring is greater with payment schemes as participation is typically voluntary from the perspective of the provider and not mandated as is the case in other MBIs.

\section{Assurance Bonds and Insurance}

Assurance or performance bonds are economic instruments commonly used in environmental management (Shogren et al., 1993; Cornwell and Costanza, 1994; Ferreira and Suslick, 2001; Bagstad et al., 2007). The aim of the bond is to ensure that the worst case cost of any damage that remains once an activity has been completed is covered (Perrings, 1989; Costanza and Perrings, 1990). This does not necessarily require an upfront payment $^{9}$, and may instead involve a bank-backed guarantee of payment in the event that the restoration is not satisfactorily undertaken by those that caused the damage, or damage is incurred that cannot be rectified. In addition to incentivizing producers to limit impacts it also ensures funds are available to rectify any damage once the activity has been undertaken. Assurance bonds have been used in a wide range of industries

\footnotetext{
${ }^{8}$ Well-defined and secure property rights typically ensure exclusivity, durability, transferability, divisibility, flexible in nature, and good quality of title.

${ }^{9}$ Some earlier schemes required an upfront posting of the bond, creating liquidity constraints in cases where the producer could not raise the bond (Shogren et al., 1993).
} 
to ensure appropriate environmental outcomes (Costanza and Perrings, 1990; Cornwell and Costanza, 1994; Gerard and Wilson, 2009), including terrestrial based mining operators in Australia and New Zealand (White et al., 2012) and elsewhere (Shogren et al., 1993; Gerard, 2000). Bonding programs in the US have been set up to incentivize compliance with environmental requirements when closing oil and gas operations. These appear to have been relatively successful, with non-compliance rates between only 1 and 9\% (Gerard and Wilson, 2009). In Western Australia, $<2 \%$ of mining bonds are called in White et al. (2012).

Assurance bonds have a number of perceived advantages. First, they ensure that sufficient resources are available for rehabilitation in the case that a firm becomes insolvent before restoration is undertaken (White et al., 2012). Further, as the money is already held by the enforcing agency it is up to the firm creating the damage to demonstrate no net loss, rather than for the enforcing agency to prove the contrary. Such a shift in the burden of proof also creates the incentive for firms to research the future environmental costs of their activities if they want to challenge the level of bond set by government (Costanza and Perrings, 1990).

Within the marine environment examples of applications of bonds are currently limited. One example is the Great Barrier Reef Marine Park, where they are a key instrument in the management of approved development activities (e.g., marina development or associated dredge disposal), requiring either a cash bond or bank guarantee ranging from $\$ 50,000$ to $\$ 500,000$ depending on the scale of the development (Great Barrier Reef Marine Park Authority, 2010). These funds have been accessed on a number of occasions to remove abandoned equipment from activities such as tourism and pearl aquaculture (ABARE, 1993; Lal and Brown, 1996; Smith et al., 2005). Financial assurance is also required for oil and gas development in the Australian marine environment, with the level of assurance based on a combination of factors, including the type of hydrocarbons, the potential spill volume and the potential area of shore impacted (APPEA, 2014). Similarly, offshore renewable energy installations in the US require a bond to ensure that decommissioning requirements are satisfactorily met after the facilities (e.g., pipelines, cables, and other structures and obstructions) are no longer required (Hill, 2011; Kaiser and Snyder, 2012). Comparable arrangements are also in place in most other countries for offshore energy developments, particularly in relation to appropriate decommissioning of offshore oil and gas facilities (Ferreira and Suslick, 2001).

Pascoe et al. (2010) outlined how bonds could be applied to manage fisheries interactions in the marine environment, with the bond returned provided fishers achieved a pre-determined performance target in terms of bycatch rates or avoidance of habitat impacts. Access to different areas of the fishery could be subject to different bond levels depending on environmental sensitivity. Individual fishers could choose to either pay the bond to access a particular area or fish elsewhere. The bond creates an incentive to either adopt technologies to minimize the chance of violation (if operating in the bonded area), or to avoid the sensitive area entirely (Pascoe et al., 2010). This provides an alternative to total exclusion, the counterfactual when implementing an MPA. Less fishing in the bonded area reduces the likelihood of the adverse environmental impact occurring, and may also benefit any fishers that remain as less pressure on the resource has the potential to result in higher catch rates (at least in the short run). Allowing non-impacting operators to remain in an area will also reduce the level of effort that is ultimately displaced to other areas or that requires buying out.

Monitoring and enforcement of such a system is potentially challenging. VMS enable identification of whether and for how long vessels are fishing in a bonded area. However, attributing any observed damage to individuals is problematic, particularly if multiple vessels are fishing in a sensitive area at the same time. While estimates of habitat damage could be derived from monitoring the amount of time fished in an area and the particular type of gear, the uncertainty around this is likely to result in legal challenges if attempts to seize bonds are made (Pascoe et al., 2010). While fishery level (rather than individual level) bonds are also an option, these may provide adverse incentives, as if fishers anticipate that the bond will be lost through the action of others there will be little incentive to limit their own impacts (Pascoe et al., 2010).

An alternative to assurance bonds is requiring developers or proponents of other activities in the marine environment to insure against the costs of restoration of (or compensation for) potential environmental damage. A potential benefit of an insurance-based system is that the risk could be sold on the insurance market, with industry members paying a premium to the insurer which reflects the insured's past performance and adoption of mitigation technologies (Pascoe et al., 2010). As with assurance bonds, the aim of insurance is to provide incentives to avoid damage, as those that are most successful (through their actions or technologies employed) will face lower premiums. Insurance markets have been used in the management of pollution in a number of countries (OECD, 2003), and there is generally a mandatory requirement for oil tankers to have appropriate insurance against oil spills in the marine environment (Chiau, 2005; Zhu, 2007). Ahvenharju et al. (2011) found that insurance-based systems were most suitable where adverse outcomes may involve high costs which individuals were unlikely to be able to meet, but the likelihood and consequences of these outcomes were highly uncertain. An advantage of insurance in this respect is that the cover is potentially openended, unlike bonds which are set at a predetermined level.

In the case of marine interactions, insurance schemes are likely to be most effective when the chance of an impact is relatively small (Holland, 2010) and highly observable, but where the consequences of the impact are relatively significant from an ecological perspective. In this case the insurance may cover the costs associated with having to exclude all other vessels from an area or close the fishery should the impact occur. For example, when vessels are monitored (e.g., via observers, electronic monitoring) the bycatch of turtles and marine mammals are readily observable. They are also potentially more avoidable than some other bycatch such as non-commercial finfish species. By and large, most fishers aim to avoid the bycatch of these species, although there is evidence that different groups within a fishery 
adopt bycatch reducing technologies at different rates (Jenkins and Garrison, 2013). Lower insurance costs for the use of more environmentally friendly fishing gear provide added incentive for their earlier adoption and development.

\section{Quota Systems}

Quota systems involve setting a total permissible level of impact, and are typically employed on the basis that when the quota is reached the vessel or fishery in question must cease operating for the remainder of that season/period. These systems impose a hard cap on the level of impact and can be applied at either the fishery level (common pool) or to individual operators. The incentives created differ depending on which level is implemented. There is a strong theoretical basis for assigning quotas at the individual level and then allowing them to be traded between participants as in a well-functioning market this makes it possible for quota to pass to operators that can use it most efficiently (Moloney and Pearse, 1979; Clark, 1980; Grafton et al., 2000). A number of quota based systems have been proposed and this section considers those based on bycatch and habitat.

\section{Bycatch Quotas}

Bycatch quotas are aimed at limiting the total incidental catch of specific species (commercial or non-commercial). A detailed review of the advantages and disadvantages of each system in terms of reducing fishing bycatch has been provided by Pascoe et al. (2010) so only the key points are discussed here.

There are a number of cases where bycatch limits for noncommercial species are imposed on fisheries, although these have mostly been related to bycatch of megafauna, particularly the more charismatic species. In the US, a total allowable catch of turtles or marine mammals is in place in several fisheries (NOAA, 2004), while limits on dolphin mortality in international tuna fisheries are also common (e.g., IATTC, 2008). New Zealand also uses output controls to manage bycatch of Hooker's sea lions in the arrow squid trawl fishery (Bache, 2003; Diamond, 2004; Chilvers, 2008). In Australia, a seabird bycatch threat abatement plan relating to bycatch during oceanic longline fishing operations currently imposes a catch rate limit (Department of Environment and Heritage, 2006). Whilst not a quota per se this approach aims to constrain the level of impact the fishery imposes and when these limits have been reached the fishery is either closed or substantial parts of its grounds are shut down (Pascoe et al., 2011). Dunn et al. (2011) suggest that such spatial and temporal closures in themselves may be appropriate management measures to limit bycatch of species irrespective of the observed level of catch.

The unintended economic impacts of common pool quotas can be substantial and greater than alternative management approaches (Pascoe et al., 2011, 2013). Abbott and Wilen (2009a) suggest that such quotas result in a "race for fish" and fisheries characterized by excessive rates of bycatch, shortened seasons, and foregone target species harvest, even when efficient (i.e., low bycatch) fishing gear is used. Delays in information collection may also make the restriction ineffective. For example, a spike in the level of demand for swordfish in 2006 resulted in a race to fish, with a large increase in the number of hooks set early in the year and the expectation that the bycatch quota would result in the fishery being closed early (Gilman et al., 2007). Alaskan bottom trawlers were also observed to have had limited success at mitigating halibut bycatch when this was managed under a common pool cap that relied on voluntary cooperation between vessels to prevent it closing the fishery before the commercial TACs were taken (Abbott and Wilen, 2010). The introduction of a formal cooperative that allocated individual quotas for target and prohibited species to its members was far more successful at altering fisher behavior though by making fishers individually responsible for their own bycatch and altering their incentives in the process (Abbott et al., 2015).

Several authors have investigated the use of individual transferable bycatch quotas (ITBQs) as a means of reducing bycatch for both megafauna (Bisack and Sutinen, 2006; Hannesson, 2006; Bisack, 2008; Ning et al., 2009) as well as fish species-either commercial (by-products) or non-commercial (Boyce, 1996; Diamond, 2004). However, relatively few real life examples of ITBQs can be found, and those that exist are focused on bycatch of commercial species. In 1996, Canada instituted an individual vessel bycatch quota (IVBQ) for its groundfish trawl fleet (Diamond, 2004), while several shark species caught as bycatch are included in the NZ quota management system. A system of individual bycatch quotas for US fisheries was found to be less successful, particularly when total quantities of bycatch were low and effectively a random event (Holland, 2010). In such cases, individual quota allocations are low and can result in illiquidity and high transactions costs. A potential consequence of this is that a fisher who is unfortunate enough to exceed their quota on a trip may find it costly to source and purchase additional quota if the unpredictable nature of the impact results in other (risk averse) fishers being reluctant to sell due to concerns that they will subsequently need it themselves. In such cases where impacts are infrequent and uncertain, greater benefits may be obtained by fishers pooling their individual quotas, reducing both financial risk and transactions costs for individuals (Holland and Jannot, 2012).

A potential limitation of quota pools is that the inefficiencies associated with common pool quotas may arise if the TAC is reached prematurely as a consequence of moral hazard, where operators can still benefit at the individual level from racing to fish (Abbott and Wilen, 2009b). Mechanisms such as revenue pooling are potential solutions to this issue but can introduce other efficiency problems due to free riding (Uchida and Baba, 2008). The formation of smaller quota sharing groups, where participants know one another and there is greater trust, may be more effective if this social capital incentivizes collaborative behavior (Pretty, 2003).

\section{Individual Habitat/Spatial Effort Quotas}

An alternative quota is the individual habitat quota which takes the form of an effort control (Holland and Schnier, 2006). These are spatial management instruments where different levels of effort penalty are applied based on the level of damage created by fishing in those areas. These quotas are tradable, allowing vessels to plan and adjust their fishing activities to minimize their own damage. Fishers "consume" their quota based on where, when 
and how they fish, with the penalty system providing incentives to either operate in areas where less damage will be incurred, or adopt fishing gear that will have a lower impact. Ideally, such a system would impose differential penalties based on gear used. Such a system provides an incentive to either reduce effort, or use more environmentally friendly gear, in sensitive habitats without the need to impose a total closure. Perhaps the only current example of this type of measure is the use of Habitat Bycatch Conservation Limits (HCBL) in the BC groundfish fishery, which imposes individual bycatch limits for cold-water corals and sponges. Initial reports appear promising and suggest that this approach has resulted in management targets being met as a result of immediate behavioral responses and substantial reductions in the total quantity of bycatch (Wallace et al., 2015).

While not designed with bycatch in mind, such a system can also be adapted as a bycatch management system. Modeling of a variable effort unit system based on fishing location proposed for an Australian tuna fishery to reduce bycatch of seabirds found that such a system could effectively control bycatch at lower cost to the industry than the current area closures (Pascoe et al., 2013).

\section{Discussion}

The preceding section illustrates the range of MBIs available as tools to alter the incentives commercial fishers face to reduce their impacts on the environment. Whilst examples of MBIs being applied in this context are still relatively limited in number and often in their infancy when compared to other industries, considering the lessons learnt from experiences to date in conjunction with known practical and theoretical limitations is informative. The continued movement toward fisheries management from a broader ecosystem based perspective and the associated requirements to reduce impacts suggest that the importance of MBIs in helping realize these goals is likely to increase into the foreseeable future. Similarly, the adoption of multiple-use zoning systems in MPAs, where fishing is permitted in some areas (e.g., Day, 2002; Boyes et al., 2007), demonstrates that there is a need for more flexible and complimentary management arrangements to ensure conservation objectives are achieved.

Whilst transferable quotas are arguably the most familiar MBI in the context of fisheries management at this point, their primary application remains as a means of managing target species catches. From a theoretical perspective, quotas, and specifically ITQs, are an economically attractive approach to effectively constrain undesirable outputs. The level of information and therefore cost that is necessary for estimating appropriate penalties to reach a particular quota is likely to be greater compared to setting a quota and adjusting. However, to attain socially optimal quota levels or optimal penalties for equivalent impact reductions, information relating to the full costs and benefits of impact abatement are necessary. Assuming acceptable compliance, the primary limiting factor of ITQs resides in their reliance on conditions that facilitate well-functioning markets. They are consequently likely to function best in situations where multiple participants and relatively frequent impacts result in high volumes of quota and trade.
Poor levels of market participation and illiquidity, limited or asymmetric information, or the existence of participants with excessive market power can result in high transaction costs, insufficient trades occurring and market failure (Farrell, 1987; Stavins, 1995). In these situations the long-run efficiency gains potentially available with ITQs will be diminished, preventing an efficient distribution of quota from being achieved (Anderson, 1991, 2008). Fisheries with ITQs for relatively infrequent and stochastic bycatch have been observed to be inefficient as uncertainty creates strong incentives to retain quota, resulting in thin and poorly functioning quota markets as a consequence (Holland, 2010). In such cases, greater formal cooperation between fishers and the pooling of quota is preferable, so that operators are less dependent on markets but can still access quota to mitigate risk efficiently (Holland and Jannot, 2012).

The examples provided in the previous section illustrate how the case specific characteristics of an environmental damage problem can influence the capacity of fishers to adapt; these are important factors for consideration since they can influence the practicality and consequent effectiveness of particular management measures. The importance of case specific characteristics is also highlighted by Holland and Jannot (2012) when discussing the appropriateness of either individual or pooled quotas but it appears that these factors often influence the choice of MBI more generally. They list frequency of bycatch by species, variance and distribution of events, numbers of events per vessel, whether risk of bycatch and profit are correlated, whether bycatch is heterogeneous across vessels, and whether real time information would reduce bycatch. For example, whilst ITQs may outperform penalties when impacts are either frequent or stochastic, if impacts are likely to occur infrequently and have a degree of predictability a system of penalties will generally be the more appropriate approach.

Penalties are flexible and can easily be adjusted to meet management objectives. If desired, penalties that increase with the level of bycatch or damage can also be implemented, increasing either progressively or in a stepwise fashion once defined thresholds are reached. To prevent them being considered just another cost of operating the level penalties are set at, or the rate at which they increase, would need to reflect the severity of the impact. In doing this, minimum levels of bycatch or damage may effectively be realized at least cost to the industry. Fishers who do what is possible to reduce bycatch but occasionally catch some will receive generally low penalties, while those who do not take measures to reduce their impact will end up with higher penalties.

For MBIs to be successful, compliance is necessary; if creating an impact does not result in the charge being imposed, quota consumed, or bond forfeited, there is no incentive to alter behavior. Ensuring compliance under systems of payments is just as important due to the obvious incentives for individual to try and game the system for their own gain. In most situations, some form of surveillance is required if compliance is to be ensured and in many fisheries the most effective way of monitoring what vessels actually catch has been through the use of onboard observers. Observer schemes can be costly 
though, and whilst it is possible to require that industry funds it this might not be practicable in reality. Lack of space can also prevent observers from working on smaller vessels. Potentially lower cost alternatives to onboard observers, such as electronic monitoring may be required and the continuing development of this technology is making it increasingly feasible (Kindt-Larsen et al., 2011; Petter Johnsen and Eliasen, 2011; Piasente et al., 2011; Seafish, 2012). The benefits of this are potentially twofold in that it could both reduce costs as well as allow vessels too small to physically accommodate an observer to effectively demonstrate compliance (and thereby continue to operate in certain areas).

For marine habitats, the use of individual habitat quotas may be the most effective means of limiting damage inside marine reserves (other than complete exclusion). These have the potential to be applied both in cases of undifferentiated habitat types where impacts are to be reduced, or in patchy environments where certain habitats need to be avoided. An attractive feature of this measure is that compliance can be easily assessed using VMS data, especially in combination with a video system that monitors fishing activity. A key challenge is to determine the total level or area of impact deemed as acceptable over any given period of time (e.g., season/year/indefinitely). If the ultimate aim is to progressively reduce aggregate impact, the total level of permissible impact may be reduced over time so that fishers must either apply less effort in that area or become more environmentally efficient (e.g., via the development of gears that result in lower levels of impact per unit of effort applied). Variants of this type of spatially related effort measure may also be applied to tackle bycatch when the areas in which the bycatch occur are discrete and do not overlap the majority of the target species distribution. A limitation to the gradual implementation of habitat quotas is in low energy environments, especially the deep sea, where habitat regeneration times may be measured in decades or centuries rather than years.

Both penalties and tradable quotas have the potential additional benefit of raising revenue that can be used for a variety of purposes, including funding conservation activities. Payments for the consumption of non-market resources by fishers to other groups are an alternative approach to offset their environmental impact. Removing predators has been seen as an economically feasible conservation action to protect turtles (Engeman et al., 2002, 2010) and seabirds (Wilcox and Donlan, 2007; Donlan and Wilcox, 2008; Pascoe et al., 2011), and fishery funded nesting site protection has been demonstrated to be a cost-effective and successful means of reducing impacts on turtles (Gjertsen et al., 2014).

An alternative to habitat quotas is the use of bonds or insurance that are either forfeited or claimed, respectively, if predetermined levels of impact are exceeded within a defined period (again typically a season or year). The level of a bond could be based on the cost of replacing damaged habitat, the cost to the rest of the fishery due to these grounds being closed for a period of time, or both. When critical impacts are likely to occur in a relatively small geographical area and additional controls outside these areas are not deemed necessary for conservation purposes bonds may be a more appropriate approach than habitat quotas as these situations are likely to results in low volumes of quota and trade. A situation that is much the same as how the management of infrequent and predictable bycatch are better suited to penalties than quotas.

\section{Concluding Remarks}

The focus of this paper has been on fishing impacts as these are prevalent in the marine environment. However, many of the instruments considered are also applicable to other marine industries, particularly the use of assurance bonds and requirements for appropriate levels of insurance against environmental damage.

A key message from the review is that no single approach is most appropriate in all circumstances and that the defining characteristics of the situation need to be identified and understood. Characteristics such as frequency of occurrence, the extent to which an impact may be predicted, and the seriousness of an impact occurring can then be used to help guide the process of determining which measure should be most effective. For example, if impacts occur infrequently and there is capacity to avoid them then penalties may be efficient; but if impacts are frequent and unpredictable then this approach is unlikely to work. Conversely, insurance markets may not be appropriate in small fisheries due to the limited ability of the insurers to spread the risk but these may be optimal measures in large fisheries.

It is well-recognized that fishers and other users of the marine environment respond to the set of incentives created by the management system within which they operate. Using this, an appropriate set of incentives can be created that limit environmental impacts. Real world experience with many of these instruments is still limited, particularly in the fisheries context where many examples remain more theoretical than empirical. However, real world experiences in the absence of adequate incentives have been demonstrated to result in undesirable outcomes such as poor environmental performance or high costs being imposed on resource users.

\section{Acknowledgments}

This work was funded under the Australian Government Commonwealth Environment Research Facilities (CERF) and the Australian Government National Environmental Research Program (NERP). The authors gratefully acknowledge feedback from Toni Cannard and Nic Bax on early versions of the manuscript and the constructive comments of Kathryn Bisack and two reviewers. 


\section{References}

ABARE. (1993). "Use of economic instruments in integrated coastal zone management," in Report Commissioned by: Coastal Zone Inquiry Resource Assessment Commission (Canberra, ACT).

Abbott, J. K., Haynie, A. C., and Reimer, M. N. (2015). Hidden flexibility: institutions, incentives, and the margins of selectivity in fishing. Land Econ. 91, 169-195. doi: 10.3368/le.91.1.169

Abbott, J. K., and Wilen, J. E. (2009a). Regulation of fisheries bycatch with common-pool output quotas. J. Environ. Econ. Manage. 57, 195-204. doi: 10.1016/j.jeem.2008.04.003

Abbott, J. K., and Wilen, J. E. (2009b). Rent dissipation and efficient rationalization in for-hire recreational fishing. J. Environ. Econ. Manage. 58, 300-314. doi: 10.1016/j.jeem.2009.03.002

Abbott, J. K., and Wilen, J. E. (2010). Voluntary cooperation in the commons? Evaluating the sea state program with reduced form and structural models. Land Econ. 86, 131-154. doi: 10.3368/le.86.1.131

Ahvenharju, S., Gilbert, Y., Illman, J., Lunabba, J., and Vehviläinen, I. (2011). The Role of the Insurance Industry in Environmental Policy in the Nordic Countries. Oslo: Nordic Innovation. Nordic Innovation Publication 2011:02.

Anderson, L. G. (1991). A note on market power in ITQ fisheries. J. Environ. Econ. Manage. 21, 291-296. doi: 10.1016/0095-0696(91)90032-E

Anderson, L. G. (2008). The control of market power in ITQ fisheries. Mar. Resour. Econ. 23, 25-35. Available online at: http://www.jstor.org/stable/42629600

Angulo-Valdés, J. A., and Hatcher, B. G. (2010). A new typology of benefits derived from marine protected areas. Mar. Policy 34, 635-644. doi: 10.1016/j.marpol.2009.12.002

APPEA. (2014). Method to Assist Titleholders in Estimating Appropriate Levels of Financial Assurance for Pollution Incidents Arising from Petroleum Activities. Perth, WA: GHD \& The Australian Petroleum Production \& Exploration Association.

Bache, S. J. (2003). Bycatch mitigation tools: selecting fisheries, setting limits, and modifying gear. Ocean Coast. Manag. 46, 103-125. doi: 10.1016/S09645691(02)00123-0

Bagstad, K. J., Stapleton, K., and D'agostino, J. R. (2007). Taxes, subsidies, and insurance as drivers of United States coastal development. Ecol. Econ. 63, 285-298. doi: 10.1016/j.ecolecon.2006.09.019

Bisack, K. D. (2008). Integrating porpoise and cod management: a comparison of days-at-sea, ITQs, and closures. Mar. Resour. Econ. 23, 361-378. Available online at: http://www.jstor.org/stable/42629623

Bisack, K. D., and Sutinen, J. G. (2006). Harbor porpoise bycatch: ITQs or time/area closures in the New England gillnet fishery. Land Econ. 82, 85-102. doi: $10.3368 /$ le.82.1.85

Bladon, A. J., Short, K. M., Mohammed, E. Y., and Milner-Gulland, E. J. (2014). Payments for ecosystem services in developing world fisheries. Fish Fish. doi: 10.1111/faf.12095. [Epub ahead of print].

Boyce, J. R. (1996). An economic analysis of the fisheries bycatch problem. J. Environ. Econ. Manage. 31, 314-336. doi: 10.1006/jeem.1996.0047

Boyes, S. J., Elliott, M., Thomson, S. M., Atkins, S., and Gilliland, P. (2007). A proposed multiple-use zoning scheme for the Irish Sea: an interpretation of current legislation through the use of GIS-based zoning approaches and effectiveness for the protection of nature conservation interests. Mar. Policy 31 , 287-298. doi: 10.1016/j.marpol.2006.08.005

Bruvoll, A., and Larsen, B. M. (2004). Greenhouse gas emissions in Norway: do carbon taxes work? Energy Policy 32, 493-505. doi: 10.1016/S03014215(03)00151-4

Bryan, J., José Pría Ramos, M., and McElderry, H. (2011). Use of an Electronic Monitoring System to Estimate Catch on Groundfish Fixed Gear Vessels in Morro Bay California - Phase II. Victoria, BC: Archipelago Marine Research Ltd.

Chiau, W.-Y. (2005). Changes in the marine pollution management system in response to the Amorgos oil spill in Taiwan. Mar. Pollut. Bull. 51, 1041-1047. doi: 10.1016/j.marpolbul.2005.02.048

Chilvers, B. L. (2008). New Zealand sea lions Phocarctos hookeri and squid trawl fisheries: bycatch problems and management options. Endanger. Species Res. 5, 193-204. doi: 10.3354/esr00086

Clark, C. W. (1980). Towards a predictive model for the economic regulation of commercial fisheries. Can. J. Fish. Aquat. Sci. 37, 1111-1129. doi: 10.1139/f $80-144$
Cornwell, L., and Costanza, R. (1994). An experimental analysis of the effectiveness of an environmental assurance bonding system on player behavior in a simulated firm. Ecol. Econ. 11, 213-226. doi: 10.1016/0921-8009(94)90202-X

Costanza, R., and Perrings, C. (1990). A flexible assurance bonding system for improved environmental management. Environ. Manage. 2, 57-75. doi: 10.1016/0921-8009(90)90013-k

Cox, A., and Schmidt, C.-C. M. R. (2006). Financial Support to Fisheries: Implications for Sustainable Development. Paris: Origanisiation for Economic Co-operation and Development.

Day, J. C. (2002). Zoning-lessons from the Great Barrier Reef Marine Park. Ocean Coast. Manag. 45, 139-156. doi: 10.1016/S0964-5691(02)00052-2

Department of Environment and Heritage. (2006). Threat Abatement Plan 2006 for the Incidental Catch (or Bycatch) of Seabirds during Oceanic Longline Fishing Operations. Canberra, ACT: Department of Environment and Heritage.

Diamond, S. L. (2004). Bycatch quotas in the Gulf of Mexico shrimp trawl fishery: can they work? Rev. Fish Biol. Fish 14, 207-237. doi: 10.1007/s11160-004-7121-0

Donlan, C., and Wilcox, C. (2008). Integrating invasive mammal eradications and biodiversity offsets for fisheries bycatch: conservation opportunities and challenges for seabirds and sea turtles. Biol. Invasions 10, 1053-1060. doi: 10.1007/s10530-007-9183-0

Dowling, N. A., Wilcox, C., Mangel, M., and Pascoe, S. (2011). Assessing opportunity and relocation costs of marine protected areas using a behavioural model of longline fleet dynamics. Fish Fish. 13, 139-157. doi: 10.1111/j.14672979.2011.00422.x

Dunn, D. C., Boustany, A. M., and Halpin, P. N. (2011). Spatio-temporal management of fisheries to reduce by-catch and increase fishing selectivity. Fish Fish. 12, 110-119. doi: 10.1111/j.1467-2979.2010.00388.x

Engeman, R. M., Duffiney, A., Braem, S., Olsen, C., Constantin, B., Small, P., et al. (2010). Dramatic and immediate improvements in insular nesting success for threatened sea turtles and shorebirds following predator management. J. Exp. Mar. Biol. Ecol. 395, 147-152. doi: 10.1016/j.jembe.2010.08.026

Engeman, R. M., Shwiff, S. A., Constantin, B., Stahl, M., and Smith, H. T. (2002). An economic analysis of predator removal approaches for protecting marine turtle nests at Hobe Sound National Wildlife Refuge. Ecol. Econ. 42, 469-478. doi: 10.1016/S0921-8009(02)00136-2

Farley, J., and Costanza, R. (2010). Payments for ecosystem services: from local to global. Ecol. Econ. 69, 2060-2068. doi: 10.1016/j.ecolecon.2010.06.010

Farrell, J. (1987). Information and the Coase theorem. J. Econ. Perspect. 1, 113-129. doi: $10.1257 /$ jep.1.2.113

Ferreira, D. F., and Suslick, S. B. (2001). Identifying potential impacts of bonding instruments on offshore oil projects. Resour. Policy 27, 43-52. doi: 10.1016/S0301-4207(01)00007-1

Francis, J., Nilsson, A., and Waruinge, D. (2002). Marine protected areas in the Eastern African region: how successful are they? AMBIO J. Hum. Environ. 31, 503-511. doi: 10.1579/0044-7447-31.7.503

Gerard, D. (2000). The law and economics of reclamation bonds. Resour. Policy 26, 189-197. doi: 10.1016/S0301-4207(00)00033-7

Gerard, D., and Wilson, E. J. (2009). Environmental bonds and the challenge of long-term carbon sequestration. J. Environ. Manage. 90, 1097-1105. doi: 10.1016/j.jenvman.2008.04.005

Gerlagh, R., and Lise, W. (2005). Carbon taxes: a drop in the ocean, or a drop that erodes the stone? The effect of carbon taxes on technological change. Ecol. Econ. 54, 241-260. doi: 10.1016/j.ecolecon.2004.12.037

Gilman, E., Kobayashi, D., Swenarton, T., Brothers, N., Dalzell, P., and KinanKelly, I. (2007). Reducing sea turtle interactions in the Hawaii-based longline swordfish fishery. Biol. Conserv. 139, 19-28. doi: 10.1016/j.biocon.2007.06.002

Gjertsen, H., Squires, D., Dutton, P. H., and Eguchi, T. (2014). Cost-effectiveness of alternative conservation strategies with application to the Pacific leatherback turtle. Conserv. Biol. 28, 140-149. doi: 10.1111/cobi.12239

Gómez-Baggethun, E., De Groot, R., Lomas, P. L., and Montes, C. (2010). The history of ecosystem services in economic theory and practice: from early notions to markets and payment schemes. Ecol. Econ. 69, 1209-1218. doi: 10.1016/j.ecolecon.2009.11.007

Gordon, H. S. (1991). The economic theory of a common-property resource: the fishery. Bull. Math. Biol. 53, 231-252. doi: 10.1007/BF024 64431

Grafton, R. Q. (1996). Individual transferable quotas: theory and practice. Rev. Fish Biol. Fish 6, 5-20. doi: 10.1007/BF00058517 
Grafton, R. Q., Squires, D., and Fox, K. J. (2000). Private property and economic efficiency: a study of a common-pool resource. J. Law Econ. 43, 679-713. doi: 10.1086/467469

Great Barrier Reef Marine Park Authority. (2010). Environmental Impact Management Policy. Townsville, QLD: Great Barrier Reef Marine Park Authority.

Gunn, J., Fraser, G., and Kimball, B. (2010). Review of the Great Barrier Reef Marine Park Structural Adjustment Package. Technical Report. Department of Environment, Heritage and the Arts, Canberra.

Hannesson, R. (2006). "ITQs for bycatches: lessons for the Tuna-Dolphin issue," in Paper Given at a Workshop Organized by the Inter-American Tropical Tuna Commission, October 10-12, 2006 (La Jolla, CA).

Hardin, G. (1968). The tragedy of the commons. Science 162, 1243-1248. doi: $10.1126 /$ science. 162.3859 .1243

Herrera, G. E. (2005). Stochastic bycatch, informational asymmetry, and discarding. J. Environ. Econ. Manage. 49, 463-483. doi: 10.1016/j.jeem.2004.05.007

Hildreth, R. G. (2008). Place-based ocean management: Emerging U.S. law and practice. Ocean Coast. Manage. 51, 659-670. doi: 10.1016/j.ocecoaman.2008.07.005

Hill, M. L. (2011). "Renewable energy on the outer continental shelf off Hawaii: implementation of a new program under the authority of the Bureau of Ocean Energy Management, Regulation and Enforcement," in OCEANS 2011 (Kona).

Hobday, A. J., Smith, A. D. M., Stobutzki, I. C., Bulman, C., Daley, R., Dambacher, J. M., et al. (2011). Ecological risk assessment for the effects of fishing. Fish. Res. 108, 372-384. doi: 10.1016/j.fishres.2011.01.013

Holland, D. S. (2010). Markets, pooling and insurance for managing bycatch in fisheries. Ecol. Econ. 70, 121-133. doi: 10.1016/j.ecolecon.2010.08.015

Holland, D., and Schnier, K. E. (2006). Individual habitat quotas for fisheries. J. Environ. Econ. Manage. 51, 72-92. doi: 10.1016/j.jeem.2005.04.005

Holland, D. S., and Jannot, J. E. (2012). Bycatch risk pools for the US West Coast Groundfish Fishery. Ecol. Econ. 78, 132-147. doi: 10.1016/j.ecolecon.2012.04.010

IATTC. (2008). Annual Report of the Inter-American Tropical Tuna Commission 2006. La Jolla, CA: Inter-American Tropical Tuna Commission.

Jenkins, L. D., and Garrison, K. (2013). Fishing gear substitution to reduce bycatch and habitat impacts: an example of social-ecological research to inform policy. Mar. Policy 38, 293-303. doi: 10.1016/j.marpol.2012.06.005

Johansson, B. (2000). "Economic instruments in practice 1: Carbon tax in Sweden," in Workshop on Innovation and the Environment (Paris: OECD) (Accessed 15 November, 2009).

Kaiser, M. J., Collie, J. S., Hall, S. J., Jennings, S., and Poiner, I. R. (2002). Modification of marine habitats by trawling activities: prognosis and solutions. Fish Fish. 3, 114-136. doi: 10.1046/j.1467-2979.2002.00079.x

Kaiser, M. J., and Snyder, B. F. (2012). Offshore Wind Energy Cost Modeling. London: Springer. doi: 10.1007/978-1-4471-2488-7

Kindt-Larsen, L., Kirkegaard, E., and Dalskov, J. (2011). Fully documented fishery: a tool to support a catch quota management system. ICES J. Mar. Sci. 68, 1606-1610. doi: 10.1093/icesjms/fsr065

Lal, P., and Brown, D. (1996). Using performance bonds as an environment management tool: The Great Barrier Reef Marine Park Authority's experience. Aust. J. Environ. Manage. 3, 86-97. doi: 10.1080/14486563.1996.10648346

MacIntosh, A., Bonyhady, T., and Wilkinson, D. (2010). Dealing with interests displaced by marine protected areas: a case study on the Great Barrier Reef Marine Park Structural Adjustment Package. Ocean Coast. Manage. 53, 581-588. doi: 10.1016/j.ocecoaman.2010.06.012

Moloney, D. G., and Pearse, P. H. (1979). Quantitative rights as an instrument for regulating commercial fisheries. J. Fish. Res. Board Canada 36, 859-866. doi: 10.1139/f79-124

Muradian, R., Corbera, E., Pascual, U., Kosoy, N., and May, P. H. (2010). Reconciling theory and practice: an alternative conceptual framework for understanding payments for environmental services. Ecol. Econ. 69, 1202-1208. doi: 10.1016/j.ecolecon.2009.11.006

Nielsen, J. R., and Mathiesen, C. (2003). Important factors influencing rule compliance in fisheries lessons from Denmark. Mar. Policy 27, 409-416. doi: 10.1016/S0308-597X(03)00024-1

Ning, F. T., Zhang, C., and Fujita, R. (2009). Quantitative evaluation of the performance of a permit auction system in reducing bycatch of sea turtles in the Hawaii Swordfish longline fishery. Mar. Policy 33, 101-105. doi: 10.1016/j.marpol.2008.05.003

NOAA. (2004). Fisheries Off West Coast States and in the Western Pacific; Western Pacific Pelagic Fisheries; Pelagic Longline Fishing Restrictions, Seasonal Area Closure, Limit on Swordfish Fishing Effort, Gear Restrictions, and Other Sea Turtle Take Mitigation Measures. Vol. 69, Federal Register, 17329-17354.

OECD. (2003). A Comparative Analysis of the Role of Insurance in the Management of Environment-related Risks - Environmental Risks and Insurance Paris: OECD.

Oremus, M., Leqata, J., and Baker, C. S. (2015). Resumption of traditional drive hunting of dolphins in the Solomon Islands in 2013. R. Soc. Open Sci. 2:140524. doi: $10.1098 /$ rsos. 140524

Pascoe, S., Innes, J., Holland, D., Fina, M., Thébaud, O., Townsend, R., et al. (2010). Use of incentive-based management systems to limit bycatch and discarding. Int. Rev. Environ. Resour. Econ. 4, 123-161. doi: 10.1561/101.00000032

Pascoe, S., Innes, J., Norman-López, A., Wilcox, C., and Dowling, N. (2013). Economic and conservation implications of a variable effort penalty system in effort-controlled fisheries. Appl. Econ. 45, 3880-3890. doi: 10.1080/00036846.2012.736941

Pascoe, S., Wilcox, C., and Donlan, C. J. (2011). Biodiversity offsets: a cost-effective interim solution to seabird bycatch in fisheries? PLOS ONE 6:e25762. doi: 10.1371/journal.pone.0025762

Perrings, C. (1989). Environmental bonds and environmental research in innovative activities. Ecol. Econ. 1, 95-110. doi: 10.1016/0921-8009(89)90026-8

Petter Johnsen, J., and Eliasen, S. (2011). Solving complex fisheries management problems: what the EU can learn from the Nordic experiences of reduction of discards. Mar. Policy 35, 130-139. doi: 10.1016/j.marpol.2010.08.011

Piasente, M., Stanley, B., Timmiss, T., McElderry, H., Jose Pria, M., and Dyas, M. (2011). Electronic onboard monitoring pilot project for the Eastern Tuna and Billfish Fishery. Canberra, ACT: Fisheries Research and Development Corporation.

Pigou, A. C. (1924). The Economics of Welfare. London: Transaction Publishers; Macmillan and Co.

Pretty, J. (2003). Social capital and the collective management of resources. Science 302, 1912-1914. doi: 10.1126/science.1090847

Sanchirico, J. N. (2003). Managing marine capture fisheries with incentive based price instruments. Public Finance Manage. 3, 67-93. doi: 10.2139/ssrn.461532

Sanchirico, J. N., Holland, D., Quigley, K., and Fina, M. (2006). Catch-quota balancing in multispecies individual fishing quotas. Mar. Policy 30, 767-785. doi: 10.1016/j.marpol.2006.02.002

Schrank, W., Árnason, R., and Hannesson, R. (eds.). (2003). The Cost of Fisheries Management. Aldershot, UK: Ashgate Publishing, Ltd.

Seafish. (2012). Fully Documented Fisheries. Grimsby: Seafish.

Sen, S. (2010). Developing a framework for displaced fishing effort programs in marine protected areas. Mar. Policy 34, 1171-1177. doi: 10.1016/j.marpol.2010.03.017

Shogren, J. F., Herriges, J. A., and Govindasamy, R. (1993). Limits to environmental bonds. Ecol. Econ. 8, 109-133. doi: 10.1016/09218009(93)90040-D

Singh, R., and Weninger, Q. (2009). Bioeconomies of scope and the discard problem in multiple-species fisheries. J. Environ. Econ. Manage. 58, 72-92. doi: 10.1016/j.jeem.2008.08.005

Smith, A., Monkivitch, J., Koloi, P., Hamilton, G., and Myers, S. (2005). "A review of Environmental Impact Assessment of tourism pontoons on the Great Barrier Reef, Great Barrier Reef Marine Park Authority, Staff Paper 2005-10," in Presented at: Environmental Institute of Australia and New Zealand (EIANZ) Conference Working on the Frontier - Environmental Sustainability in Practice (Christchurch: Hotel Grand Chancellor).

Stavins, R. N. (1995). Transaction costs and tradeable permits. J. Environ. Econ. Manage. 29, 133-148. doi: 10.1006/jeem.1995.1036

Stewardson, C. (2007). National Assessment of Interactions between Humans and Seals: Fisheries, Aquaculture and Tourism. Canberra, ACT: Australian Government Department of Agriculture, Fisheries and Forestry.

Sutinen, J. G., Rieser, A., and Gauvin, J. R. (1990). Measuring and explaining noncompliance in federally managed fisheries. Ocean Dev. Int. Law 21, 335-372. doi: 10.1080/00908329009545942

Tasker, M. L., Camphuysen, C. J., Cooper, J., Garthe, S., Montevecchi, W. A., and Blaber, S. J. M. (2000). The impacts of fishing on marine birds. ICES J. Mar. Sci. 57, 531-547. doi: 10.1006/jmsc.2000.0714 
Tietenberg, T. H. (2013). Reflections-carbon pricing in practice. Rev. Environ. Econ. Policy 7, 313-329. doi: 10.1093/reep/ret008

Townsend, R. E. (1985). On "capital-stuffing" in regulated fisheries. Land Econ. 61, 195-197. doi: 10.2307/3145812

Trebilco, R., Gales, R., Lawrence, E., Alderman, R., Robertson, G., and Baker, G. B. (2010). Characterizing seabird bycatch in the eastern Australian tuna and billfish pelagic longline fishery in relation to temporal, spatial and biological influences. Aquat. Conserv. Mar. Freshw. Ecosystems 20, 531-542. doi: $10.1002 /$ aqc. 1115

Uchida, H., and Baba, O. (2008). "Fishery management and the pooling arrangement in the Sakuraebi Fishery in Japan," in Case studies in fisheries self-governance, eds R. Townsend, R. Shotton and H. Uchida. (Rome: Food \& Agriculture Organization of the United Nations), 175.

Wallace, S., Turris, B., Driscoll, J., Bodtker, K., Mose, B., and Munro, G. (2015). Canada's pacific groundfish trawl habitat agreement: a global first in an ecosystem approach to bottom trawl impacts. Mar. Policy 60, 240-248. doi: 10.1016/j.marpol.2015.06.028

White, B., Doole, G. J., Pannell, D. J., and Florec, V. (2012). Optimal environmental policy design for mine rehabilitation and pollution with a risk of noncompliance owing to firm insolvency. Aust. J. Agric. Resour. Econ. 56, 280-301. doi: $10.1111 /$ j.1467-8489.2012.00591.x
Wilcox, C., and Donlan, C. J. (2007). Compensatory mitigation as a solution to fisheries bycatch biodiversity conservation conflicts. Front. Ecol. Environ. 5, 325-331. doi: 10.1890/1540-9295(2007)5[325:CMAAST] 2.0.CO;2

Witt, M. J., and Godley, B. J. (2007). A step towards seascape scale conservation: using Vessel Monitoring Systems (VMS) to map fishing activity. PLoS ONE 2:e1111. doi: 10.1371/journal.pone.0001111

Zhu, L. (2007). Compulsory Insurance and Compensation for Bunker Oil Pollution Damage. New York, NY: Springer-Verlag Berlin Heidelberg.

Conflict of Interest Statement: The authors declare that the research was conducted in the absence of any commercial or financial relationships that could be construed as a potential conflict of interest.

Copyright (c) 2015 Innes, Pascoe, Wilcox, Jennings and Paredes. This is an openaccess article distributed under the terms of the Creative Commons Attribution License (CC BY). The use, distribution or reproduction in other forums is permitted, provided the original author(s) or licensor are credited and that the original publication in this journal is cited, in accordance with accepted academic practice. No use, distribution or reproduction is permitted which does not comply with these terms. 